\title{
Guidelines for Education in Business and Information Systems Engineering at Tertiary Institutions
}

\author{
Reinhard Jung • Christiane Lehrer
}

Published online: 3 May 2017

(c) The Author(s) 2017. This article is an open access publication

\begin{abstract}
The paper presents guidelines for education in business and information systems engineering (BISE) at tertiary institutions, which were designed by a working group comprising domain experts, both from academia and practice. The guidelines contain the learning outcomes in Bachelor's and Master's degree programs, in particular, the key subject-specific, social, and personal skills needed by BISE graduates. Moreover, corresponding occupational profiles, the specific skills required, as well as the essential and typical learning content for BISE education are described. Furthermore, detailed recommendations for the design of Bachelor's and Master's degrees curricula and sub-curricula in BISE, business administration, and computer science, respectively, are provided. The presented guidelines serve several purposes. Providing common directions for BISE education is aiming to support personnel in charge of curriculum development and to assist students in program and career choice.
\end{abstract}

Keywords Business and information systems engineering · Guidelines - Education · Curriculum · Occupational profile $\cdot$ Study profile $\cdot$ Skills $\cdot$ Educational areas

Any system or product names mentioned in the guidelines should be considered as examples, based on the reference year 2016 .

Prof. Dr. R. Jung · Ass.-Prof. Dr. C. Lehrer ( $\square)$

Institute of Information Management, University of St. Gallen, 9000 St. Gallen, Switzerland

e-mail: christiane.lehrer@unisg.ch

Prof. Dr. R. Jung

e-mail: reinhard.jung@unisg.ch

\section{Introduction}

The academic discipline of business and information systems engineering (BISE) (Wirtschaftsinformatik) combines knowledge areas of economics, especially business administration, and computer science. The discipline deals with information systems (IS) in business, public administration, and the private sphere. IS as socio-technical systems and application systems as automated subsystems of IS are being studied. Research and education in BISE show strong similarities to the international IS discipline regarding the addressed topics and interdisciplinary nature. Compared to IS, BISE places more emphasis on applied computer science and the design of IT artefacts.

In this paper, we present guidelines for education in BISE at tertiary institutions in German-speaking countries. Similar advances have been made for degree programs in IS, for example, by the Association for Computing Machinery (ACM) and the Association for Information Systems (AIS) $[1,2]$. Apart from a few local exceptions, to the best of our knowledge further curriculum guidelines are scarce to date. The presented guidelines serve several purposes. By providing common directions for BISE education, we aim to support schools, departments, and individual faculty members in charge of curriculum development and to assist students in program and career choice. For international IS scholars who intend to develop guidelines for their own countries or regions, the development process of the presented guidelines can serve as a valuable example.

Curriculum recommendations for BISE education have been in place in the German-speaking countries since 1984. Rapid technological advancement, combined with progressing consolidation within the subject, meant that various revisions were necessary over the past decades. Since the publication of the previous revision in 2007, we witnessed 
profound changes in the economy and society - induced, among other reasons, by digitization and globalization. Moreover, within organizations technology and thereby the IT department are becoming increasingly important for driving innovation. These developments again altered the requirements for higher education in BISE and motivated a revision. The present guidelines reflect upon these changes and address the current and future demands that academic and professional practice has on graduates. It builds on the guidelines from 2007 by way of updates and additions.

The guidelines were developed by the authors together with a working group comprising 38 domain experts, both from academia and practice. The working group was formally established in March 2016 on behalf of the Academic Commission for Business Informatics (Wissenschaftliche Kommission Wirtschaftsinformatik, WKWI) of the German Academic Association for Business Research (Verband der Hochschullehrer für Betriebswirtschaft, VHB) and the Department of Business Informatics of the German Informatics Society (Gesellschaft für Informatik, GI). The guidelines were formally approved by the GI in January 2017 and by the WKWI in February 2017 [3]. The working group comprised the following persons: Prof. Dr. Jörg Becker (University of Münster), Prof. Dr. Alexander Benlian (TU Darmstadt), Prof. Dr. Daniel Beverungen (University of Paderborn), Prof. Dr. Carsten Felden (TU Bergakademie Freiberg), Prof. Dr. Peter Fettke (Saarland University, German Research Center for Artificial Intelligence $\mathrm{GmbH}$ ), Prof. Dr.-Ing. Axel Hahn (University of Oldenburg), Prof. Dr. Thomas Hess (LMU Munich), Prof. Dr. Christian Janiesch (University of Würzburg), Prof. Dr. Reinhard Jung (University of St.Gallen, Head of the Working Group), Prof. Dr. Dimitris Karagiannis (University of Vienna), Prof. Dr. Franz Lehner (University of Passau), Prof. Dr. Christiane Lehrer (University of St.Gallen), Prof. Dr. Jan Marco Leimeister (University of St.Gallen, University of Kassel), Prof. Dr. Susanne Leist (University of Regensburg), Prof. Dr.-Ing. Jorge Marx Gómez (University of Oldenburg), Prof. Dr. Marco C. Meier (University of Augsburg), Prof. Dr. Jan Mendling (Vienna University of Economics and Business), Prof. Dr. Lars Mönch (University of Hagen), Prof. Dr. Christian Müller (TH Wildau), Prof. Dr. Andreas Oberweis (Karlsruhe Institute of Technology), Prof. Dr. Jan Pawlowski (Ruhr West University of Applied Sciences), Prof. Dr. Key Pousttchi (University of Potsdam), Prof. Dr. René Riedl (University of Applied Sciences Upper Austria, University of Linz), Prof. Dr. Stefan Sackmann (University of HalleWittenberg), Prof. Dr.-Ing. Jürgen Sauer (University of Oldenburg), Prof. Dr. Detlef Schoder (University of Cologne), Prof. Dr. Matthias Schumann (University of Göttingen), Prof. Dr. Elmar J. Sinz (University of Bamberg), Prof. Dr. Stefan Smolnik (University of Hagen), Prof. Dr. Stefan Stieglitz (University of Duisburg-Essen), Prof. Dr.
Susanne Strahringer (TU Dresden), Prof. Dr. Frédéric Thiesse (University of Würzburg), Prof. Dr.-Ing. Martin Wolf (University of Applied Sciences Aachen), Prof. Dr. Steffen Zimmermann (University of Innsbruck). Furthermore, comments from practitioners in managerial or executive roles have been incorporated. Specifically, the following participated: Peter Kraus (formerly of ZF Friedrichshafen), Dr. Heinz Linss (Kienbaum Management Consultants), Andreas Maier (AXA Winterthur), and Hon.Prof. Dr. Hermann Sikora (Raiffeisen Software GmbH).

Higher education in the discipline of BISE is practiced under various frameworks regarding target groups, institutionalization, and the focus of its content. The various forms include BISE as a standalone Bachelor's or Master's degree program at universities and universities of applied sciences. In addition, students can acquire selected skills in the subject area through the study of BISE as an elective, minor, or major field of study in a Bachelor's or Master's degree in economics, computer science, and possibly even in engineering. In addition, specialized Master's degrees in economics have been established in recent years, such as business innovation programs. These are technology-oriented and include BISE components as well. A minimal version, as often found in economics programs, conveys BISE in the form of one or more compulsory and/or elective courses.

In this recommendation, the essential learning content for BISE education and its relations to neighboring disciplines especially to business administration and computer science are described. Given the variety of educational options, it is not possible to define a consistent and generally valid distribution of learning content with respect to courses, credits, and hours. In Chapter 7, however, recommendations for the most common variants are defined. In contrast to previous guidelines, we included for the first time a skills model developed in four main steps. First, we defined relevant occupational profiles for BISE graduates and the specific skills needed to perform the role effectively. Second, the educational targets in Bachelor's and Master's degree programs were formulated. In particular, we defined the targeted subject-specific, social, and personal skills that are of particular relevance within BISE. Third, the main educational areas considered by the working group to be essential and typical for BISE education were described. Sub-working groups refined the learning content of the main educational areas in several revisions. Fourth, the involved practitioners validated the occupational profiles, targeted skills, and main educational areas and their feedback was incorporated.

The paper is organized as follows. It is based on a description of the subject matter and objectives of the academic discipline of BISE (Chapter 2). Subsequently, the educational objectives in Bachelor's and Master's degree programs are presented, as well as the targeted subjectspecific, social, and personal skills (Chapter 3). In addition, 
sample occupational profiles for BISE graduates are outlined. These can provide guidance for curriculum development, also assisting students in program and career choice (Chapter 4). The following chapter describes the main educational areas considered by the working group to be essential and typical for BISE education (Chapter 5). Chapter 6 tackles the requirements that need to be considered when BISE is included within a different degree program. Chapter 7 provides quantitative recommendations for the design of various curricula. Finally, the organizational and structural requirements for BISE courses are described, differentiated for universities and universities of applied sciences (Chapter 8).

\section{Subject Matter and Objectives of BISE as a Discipline}

The subject matters of BISE are IS in business, public administration, and the private sphere. IS are socio-technical systems that include human and machine components (subsystems) [4]. Application systems are automated IS subsystems. In general, they include the associated hardware, system software, communications equipment, and application software. In the narrower sense, it is referred to with the term application software. Modern IS play a central role in almost all economic, political, and social contexts. They are found in companies, in public administration, and with consumers. They represent a fundamental prerequisite for the increasing digitization of the economy and society and thus will gain even more importance in the future.

The objectives of the academic discipline of BISE are [4]:

(a) the (further) development of theories, methods, and tools for obtaining intersubjectively verifiable findings regarding IS,

(b) design-oriented construction of IS and the necessary (further) development of concepts, approaches, models, methods, tools and (modeling) languages,

(c) the achievement of a scientific understanding of use, acceptance, management, and controllability of IS and of its various system elements, such as with regard to the behavior of people in and with these systems as the responsible authorities or users,

(d) an above-all economical assessment of risk, benefit, and efficiency issues in the design and use of IS, the value-creation processes thus modified, and the related strategic and organizational impacts on individuals, groups, companies, industries, and economic areas, and

(e) the prognosis of technical and non-technical developments and effects stemming from the use of IS.

As an interdisciplinary subject, BISE integrates knowledge areas of economics (especially business administration) and computer science (Fig. 1).

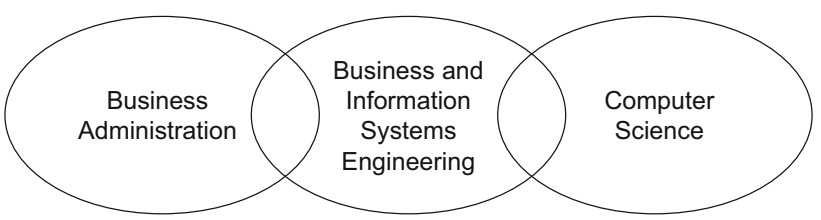

Fig. 1 BISE as an interdisciplinary subject

BISE is a standalone, interdisciplinary academic discipline. It has its roots in computer science and economics, especially in business administration. As an applied subject, BISE expands upon and integrates these disciplines. It also has its own methods and tools. In addition, topics from BISE - such as data analytics - are diffusing increasingly into business administration and computer science. Other neighboring disciplines important for BISE are mathematics, statistics, sociology, psychology, and law.

In determining the learning content in a specific case, it must be considered whether or to what extent the learning content in the disciplines of business administration and computer science is being taught outside of the subject of BISE. The two following scenarios are typical:

(a) BISE education is carried out by an economics faculty: It can generally be assumed that the business administration learning content is already covered. It must then be ensured that the relevant learning content from computer science is taught. The latter can be carried out by a computer sciences faculty should one exist. Otherwise, computer science learning content must be taught as part of BISE education.

(b) BISE education is carried out by a computer science faculty: It can generally be assumed that the relevant computer science learning content within BISE is already covered. In this case, it must be ensured that the relevant business administration learning content is taught as part of the education program.

\section{Educational Targets}

The study of BISE is conceptually and methodologically based and, at the same time, orientated toward the career and labor markets. It is thus a fundamental objective to prepare students for a labor market evolving due to technological changes and to empower them, as future decision makers, to recognize and evaluate technological potentials and to help in shaping the resulting changes. For graduates, these studies open up career opportunities in various economic branches, including technology companies that act as IT solution suppliers, in so-called user companies that use IT solutions, in consultancies, and in public 
administration. Another prospect is self-employed activity as an entrepreneur, such as within start-up structures. Likewise, commencing with doctoral studies is possible, which opens further career opportunities in the industry and in academia. Against this backdrop, studies should alongside the relevant subject-specific and methodological skills - also teach social and personal skills, to be able to successfully help in shaping technology-driven changes in organizations and in society.

Besides a strong interest in IT and business of the candidates, key prerequisites for higher education in BISE also include a strong creative drive and good analytical and design skills with respect to holistic, integrative approaches. In addition, computer skills (e.g., dealing with end user software and relevant web applications) and a good knowledge of the English language are preconditions, both because BISE issues have global dimensions (e.g., offshoring, supply chain management) and because large amounts of the relevant literature are in English.

The present guidelines contain for the first time a list of the skills that students should acquire. It helps those responsible for the degree programs to define the skills to be attained (learning outcomes) for degrees and individual modules so that they can be taught, developed and tested. Considering skills is also required in terms of accreditation. The skills model shown below has two basic dimensions: firstly, the subject-specific skills, and secondly the social and personal skills that are of particular relevance within BISE. Subject-specific skills as well as social and personal skills should not be taught in a standalone way. Rather, they should ideally be integrated.

The subject-specific skills and the learning content upon which they are based (see Chapter 5) were prepared by the working group based on the guidelines from 2007 by implementing updates and additions. The social and personal skills represent a selection of the skills described in literature and held by the working group to be of particular relevance for BISE graduates. A validation of this assessment was carried out by the practitioners involved. It is not intended that acquisition of social and personal skills will take place in dedicated courses alone. Instead, specific teaching formats (e.g., project and group work) are to ensure that the social and personal skills are taught in a way interlocked with the acquisition of subject-specific skills.

\subsection{Subject-Specific Skills}

Education in BISE teaches theoretically sound concepts and methods that enable students to analyze, design, implement, operate, and use IS within and between organizations. It is intended that as future decision-makers, they will be able to understand the potential benefits of targeted provision of information, in particular for information, goods, and cash flows and to make these a reality via appropriate use of IS. Students thus require broad and (in selected subtopics) in-depth technical knowledge relating to methods of designing by means of IT. They also require a solid understanding of possible areas of application within organizations. The focus is always on the intended ability to design and deploy IS toward the implementation of corporate goals. This includes reflecting on products, services, and processes within and between organizations. Paying heed to design-related tasks in the development of application systems requires an understanding of the effect mechanisms of software systems. Accordingly, it is essential that students also develop programs themselves.

The learning content providing the subject-specific skills to the students is detailed in Chapter 5 structured into main educational areas. Therefore, these skills are described here in abstract terms only.

\section{Subject-specific skills}

Understanding domains of IS application within organizations and for consumers

Analyzing, designing, implementing, operating, and using IS in single instances and between organizations

Exploiting potential benefits of targeted information provisioning, in particular for information, goods, and cash flows by appropriate deployment of IS

Understanding the functioning of software systems

Developing software

\subsection{Social and Personal Skills}

In addition to subject-specific skills, key social and personal skills are also taught. Being professionally active in BISE often means assuming a "translation role" between the languages found in business administration and those found in the technical arena. This necessitates high requirements being set in terms of certain social skills (including cooperation and communication skills for working in interdisciplinary and possibly distributed project teams, even across countries and continents; presentation and discussion of work results, also in foreign languages). The acquisition of social and personal skills is done partially in an implicit manner, via the acquisition of subject-specific skills. In addition, modules in which relevant skills are taught and practiced are also a high priority. These include seminars and project work in which teams work on real-life tasks and present the results under realistic conditions. 
Social skills

Ability to lead teams (leadership skills)

Showing interest in other people and their concerns (empathy)

Ability to inspire others for a cause (ability to motivate)

Knowing and valuing the prevailing differences in different cultures (intercultural competence)

Constructively dealing with different perspectives and interests, identifying causes in conflict situations and developing solutions (conflict management)

Defining, committing to, and working toward team goals together, dealing with criticism (teamwork, cooperativeness, ability to take criticism)

Being self-assured and confident in negotiations and representing one's own interests and those of the team well (ability to negotiate and discuss)

Sticking to rules and agreements and carrying out responsibilities with the promised quality (reliability)

In addition, students gain personal skills that motivate and empower them for lifelong learning. In particular, this includes learning skills, problem-solving skills, and the ability to reflect autonomously on work experiences and translate them into adjusted behavior.

\section{Personal skills}

Individual skills

Ability and willingness to independently acquire new knowledge and to learn from successes and failures (learning skills and motivation)

To engage with changing conditions and deal with changing situations (adaptability)

Knowing one's own scope of possibility for decision making and the responsibility that goes with this, obtaining the necessary information, developing alternatives, setting priorities, and finding a solution within a reasonable time (decision-making ability)

Assessing the consequences of one's decisions and actions for oneself and others and forming independent judgment (willingness to take responsibility)

Ability to perceive circumstances or situations as ethically important, to formulate normative rules of conduct and to justify them (ethical competence)

Willingness to apply and commit oneself (initiative)

Thinking, deciding, and acting entrepreneurially (entrepreneurship)

Constructively dealing with difficult conditions such as high pressure, resistance, disruptions, and performing well during difficult phases (endurance/stamina)

Ability to research sources and asses them in a reflective way, to structure situations sensibly and properly delineate one's own ideas from those of others (working scientifically)

Writing and speaking clearly and understandably, using situation-appropriate vocabulary (ability to express oneself)

Acting confidently, trustworthily, and persuasively according to the specific situation (appearance) continued

Personal skills

Activity and implementation-oriented skills

Understanding and organizing extensive and complex relationships in a short time, filtering out what's most important and representing it in a generally intelligible way (ability to analyze, present, and communicate)

Assessing situations and deriving consequences and solutions (assessment and problem-solving ability)

Recognizing customer/partner etc. needs and addressing them adequately in terms of service and quality (customer orientation)

Including goals within work tasks and making optimal use of available resources (organizational capacity)

Running projects according to requirements and restrictions (project management)

\section{Sample Occupational Profiles and Specific Skills}

Studying BISE sets the foundations for interesting positions in various professional fields, such as IT management, business consultancy, IT startups, and process management. In the following, sample occupational profiles - to be understood as model profiles - are briefly presented, as are the specific skills. In addition, there are of course other professions in which BISE graduates are already active today, such as application system developers and chief digital officers. With respect to dynamic technological developments, it is to be expected that new model occupational profiles will arise.

\subsection{IT Manager}

IT management is a leadership and supervisory role in which one aims for effective and efficient information supply and use of IT. IT managers lead organizations such that the value contribution IT makes to organizational objectives and results is maximized and the risks associated with the use of IT are minimized. As part of the digital transformation of organizations and their business processes, IT managers have a crucial structuring role within companies. BISE graduates should be prepared for roles as leaders within organizations. They can begin by taking entry level IT positions (e.g., business analyst, project manager, process manager, software architect, software developer, enterprise architect) and, with some years of professional experience, take management positions (e.g., chief information officer, chief architect, IT strategist). Moreover, they can be active in departments such as manufacturing, materials management, controlling, marketing, or innovation management.

Graduates trained to be IT managers have the skills to:

- convert business strategies into IT strategies and subsequently operationalize these with regard to 
infrastructure and application management and IT operations,

- identify business opportunities, risks, and implications of new digital technologies and to continuously recognize and evaluate solutions for the entire company,

- develop business models for digital products and services,

- align existing and new IT solutions, products, and processes systematically to the requirements of internal and external customers and to lead implementation projects,

- shape organizations with respect to information supply (especially process design, process optimization, and organizational structure),

- organize and steer large, complex change programs,

- organize and steer IT operations.

\subsection{Business Consultant}

Consultancy is a typical field to which BISE graduates can commit themselves. This is where they can be involved in strategic and operational IT consultancy. As consultants with a focus on strategic consultancy, they support organizations - depending on professional experience - in various decisions related to IT. These include IT strategy, IT portfolio management, and enterprise architecture, as well as mergers, acquisitions, or the introduction of new IT. Business advisers who focus on operational IT consultancy provide support in areas such as the design of IS and in the selection and implementation of application systems.

Graduates trained to be IT consultants have the skills to:

- identify problems and potential improvements in organizations and to translate the business requirements into appropriate technical and non-technical solutions,

- strategically align and implement IT architectures/ infrastructures and application systems according to the needs of customers and the organization in general,

- develop project strategies and manage (sub)projects,

- critically evaluate business opportunities, develop business models, and plan/steer their implementation.

\subsection{Technology Entrepreneur}

BISE graduates have many of the prerequisites to develop technology-based innovations and, in doing so as entrepreneurs, to establish and lead companies. In addition, as intrapreneurs, they can assume corresponding management roles in innovative companies or spin-offs. Entrepreneurial thinking, decision-making, and action in the digital age requires a comprehensive interdisciplinary perspective that cross-sects with multiple management disciplines and technology fields. To bring an innovative business idea into the market, one must master how to deal with uncertainty, international competition, limited resources, and new technologies. Also required are skills in the development, analysis, and implementation of business models for startups and established companies.

Graduates trained to be technology entrepreneurs have the skills to:

- recognize or create business opportunities and develop strategies and apply methods to exploit these opportunities,

- identify and evaluate potentials, risks, and impacts of new technologies and solutions and responsibly utilize them,

- develop and implement innovative and scalable business models,

- economically deploy financial, staff, social, organizational, and technological resources to find customer solutions,

- push on with the implementation of a new business idea within a startup or established company, effectively and with focus.

\subsection{Process Manager}

Process managers look at a company as an interdepartmental value chain and strive to identify and improve processes. With modern IT, outdated structures can be eliminated, media breaks avoided, processes streamlined, and systems integrated. To this end, processes are analyzed and recurring patterns are identified and subsequently documented within reference models as best practice. To improve internal processes within companies - so-called workflows - process managers eliminate superfluous steps, simplify the way processes unfold and automate them by deploying suitable IS. Through this improved coordination of various processes and systems in relation to the organizational structure of a company, process managers ensure efficient use of resources. Process managers are needed in all economic sectors in which administration is highly complex (e.g., banks, insurance companies, or commerce), as well as in public administration.

Graduates trained to be process managers have the skills to:

- understand, document, and analyze business processes,

- model and structure processes, data, rules, and other business artifacts, and to embed these within an enterprise architecture,

- investigate complex relationships using analytical methods,

- recognize, evaluate, and lastingly implement potentials for structural process improvements, 
- monitor operations, identify problems using appropriate methods and indicators at an early stage, and develop process-based solutions,

- continually develop and improve organizations.

\section{Main Educational Areas}

The learning content which follows is structured in main educational areas and is considered by the working group to be essential and typical for BISE education. It is, however, not expected that all learning content mentioned for any specific degree will be fully covered. Individual prioritizations are possible. If these are made, efforts should still be made to ensure an overview of other learning content, thus providing students with a complete picture of the issues within BISE.

\subsection{Subject and Context}

(a) Subject matter of BISE: overview of subdomains, relations between BISE and neighboring disciplines.

(b) Types and core elements of IS in organizations and value networks; IT artifacts.

(c) Importance of BISE for organizations and economies.

(d) Digitization and globalization and their implications for BISE.

(e) IT industry: software companies and Internet providers (business models, markets, and management concepts), other IT companies at a glance (including service providers).

(f) Foundations and methods of empirical and designoriented research.

\subsection{Economic Foundations}

(a) Business administration foundations: procurement, investment and finance, marketing, human resources and organization, product development, accounting, strategic management, value chains and networks, value-oriented corporate management.

(b) Business administration foundations with particular relevance to BISE, e.g., organization, entrepreneurship, innovation management, production and logistics, service management, controlling, corporate governance.

(c) Selected economic foundations: national accounting, financial and economic policy, markets (goods, finance, labor markets), international economic relations, key concepts (e.g., trade cycle, exchange rate, interest rate).

\subsection{Foundations of Computer Science}

(a) Mathematical foundations of computer science (including discrete structures, complexity, and computability).

(b) Foundations of software engineering (including process models and development tools), in particular object-oriented modeling (e.g., Unified Modeling Language), programming and architectures of application systems.

(c) Programming with (object-oriented) programming languages (e.g., Java).

(d) Specific algorithms, data, and data structures (e.g., planning and optimization algorithms in the context of ERP systems).

(e) Design and implementation of database systems (e.g., implementation and optimization of databases and database management systems).

(f) Web engineering (e.g., technologies and applications on the Internet).

(g) Optional additional topics from applied computer science (e.g., operating systems, computer networks, and distributed systems).

\subsection{Further Foundations}

(a) Statistics and mathematics for BISE, especially discrete mathematics, linear algebra, graph theory, combinatorics, stochastics, methods of deductive and inductive statistics, econometrics, selected aspects of logic.

(b) Behavior science foundations: organizational psychology, acceptance, group decision-making, cognitive psychology, behavioral economics, foundations from neuroscience.

(c) Business law: private law, labor law, copyright law, intellectual property law, media law, telecommunications law, each with particular emphasis on information processing (e.g., privacy, product liability and copyright protection for software, participation in automation projects, internet access), IT Compliance.

(d) Ethics and sustainability.

\subsection{Data Management}

(a) Data models and database systems: enterprise data models, conceptual data modeling (in particular by means of entity-relationship model, semantic object model, Unified Modeling Language); logical data models and database schemas. 
(b) Relational databases and database management systems: relational algebra, database languages (esp. Structured Query Language), transactions.

(c) Non-relational database systems: Not only SQL, CAP theorem, column-oriented databases, in-memory databases, data lakes, collection and storage of large and heterogeneous data sets.

(d) Data warehousing: data management (extraction, transformation, loading), multidimensional data models, Multidimensional Expressions, architectures (e.g., hub and spoke), operational data stores and data marts, Lambda architecture, distinguishing operational and analytical data models and database systems.

(e) Applications in master and metadata management, data quality management, data integration (business documents, data interfaces, especially Extensible Markup Language), repository systems, ontologies, semantic web.

\subsection{Process Management}

(a) Strategic process management: process organization, strategic alignment, business process management lifecycle, maturity models.

(b) Enterprise modeling, e.g., with architecture of integrated information systems, semantic object model, multi-perspective enterprise modelling or comparable modeling frameworks; modeling methods, metamodeling, methods design.

(c) Process modeling, e.g., with business process model and notation, event-driven process chains or comparable modeling frameworks; complementary modeling languages for data, decisions, and rules, e.g., entity-relationship model or decision model and notation, business rule management.

(d) Process analysis and mining: descriptive vs. prescriptive process models, quantitative and qualitative process analysis, business activity monitoring, process warehouse, process simulation, process compliance and compliance management, process mining algorithms such as alpha algorithm; analysis of process models with suitable query languages (model query).

(e) Process execution and monitoring: workflow management, enterprise resource planning, web service composition, choreography/orchestration, businessprocess-management systems, event-driven business process management, process simulation at theoretical and practical levels.

(f) Process optimization and continuous improvement: models and methods of quality management, six- sigma method for error-free business processes, benchmarking.

(g) Domain-specific reference models, e.g., for industry, banking, retail, finance, tourism, and e-government.

\subsection{Information Management}

(a) Fundamental concepts: data/information/knowledge and information management, historical roots, structuring approaches from information management and its interaction with other BISE topic areas, especially the digital transformation (e.g., newer forms of division of labor and value creation, new management roles within the digital transformation).

(b) Value contribution of IT: IT as a competitive factor, differentiating effect of IT.

(c) IT Governance: role of IT in companies and organizations, interaction between IT and business departments, internal organization of the IT department, roles of a chief information officer, IT risk management.

(d) IT strategy: formulation of an IT strategy and alignment with corporate strategy (strategic alignment), differentiation of IS strategy and IT strategy, determining the product and service portfolio to be realized by the IT department.

(e) Sourcing of IT: insourcing and outsourcing, reasons, evaluation of variants, contract design (e.g., in terms of service level agreements), managing supplier relationships.

(f) Software: sources, selection, implementation and management (make-or-buy decision, configuration and parameterization of standard software, process models for selection and introduction of standard software, management concepts (especially the cloud), software-as-a-service, on-premises use, mobile applications (apps), licensing models).

(g) IT landscape: management of information and communication technology infrastructure and IT security as well as the product and service portfolio of the IT department; architecture overview, planning, integration and consolidation, operations.

(h) IT controlling: controlling instruments (e.g., IT balanced scorecard), economic efficiency of IT, IT cost allocation, frameworks (e.g., CoBIT).

(i) Project management: project initiation, planning and management.

(j) IT compliance and legal framework of information management, e.g., data security, privacy, co-determination, contract design, copyright protection for software. 
5.8 Development and Operation of Information Systems

(a) Problem analysis and requirements specification: use of languages for modeling business processes, operations and workflows, objects, data, and features (e.g., architecture of integrated information systems, business process model and notation, semantic object model, the Unified Modeling Language); consideration of requirements for strategic information system planning and Business-IT alignment, compliance requirements, risk management.

(b) Architectural design: architectural models (e.g., web architecture, service-oriented architecture, peer-topeer architectures, component-oriented architectures, client-server architectures), architectural styles (e.g., representational state transfer), enterprise architecture management, cloud computing, software-as-aservice, component interfaces, architecture development.

(c) Program development and testing: development tools, languages, and libraries, development platforms (e.g., JavaEE, .NET, the Android platform, the iOS platform, Windows-platform apps, OS X apps), use of database systems and data services, reuse (e.g., patterns), test methods and strategies (testdriven development, continuous integration), modeldriven approaches, secure software development.

(d) Automation: determination of degree and form of automation for information systems, design of human-computer interface (e.g., human-computer interaction, usability, accessibility).

(e) System integration: integration concepts, selection of system components (full service versus best-of-breed approaches).

(f) Process models for the development of information systems: V-Model XT, rational unified process, classical process models (waterfall model, prototyping, spiral model), agile approach (eXtreme programming, Scrum), process models with specific focus (e.g., business intelligence projects).

(g) Operation of information systems: IT service, IT service management, cooperation agreements, service level agreements, monitoring operating conditions, reference models (e.g., IT infrastructure library), life cycle of IT systems (replacement of legacy systems and continuous renewal and development), maintenance of IT systems, ensuring information security.

(h) Integration of information systems: Integration concepts, horizontal and vertical integration, integration across organizational boundaries, networking of information systems with things (smart objects) and operational resources (e.g., in the internet of things or as cyber-physical systems); integration of corporate core systems with document and workflow management systems, with social software and collaboration systems.

\subsection{Corporate Core Systems}

(a) Enterprise resource planning: function-oriented ERP modules or application systems (e.g., human resource management, accounting, finance), illustration and integration of business processes in ERP (e.g., order processing); sector-dependent and sectorindependent ERP systems.

(b) Supply chain management: strategic planning of supply chains and networks, network-wide planning, management, control, and monitoring of supply chains (supply chain event/performance management), advanced planning and scheduling, supplier relationship management.

(c) Customer relationship management: information technology for building and maintaining client relationships; subsystems (e.g., sales force automation, call center, customer service, collaborative and analytical customer relationship management) and integration thereof.

(d) Product lifecycle management including product data management: modeling and structuring of technical and workflow-related product data; strategic planning of production, management, distribution, and use processes for product data in value chain networks for the entire product life cycle, starting with the product idea and development.

(e) Economic branch-oriented information systems, especially in industry (e.g., ERP modules that deal with production planning and control, manufacturing execution systems), commerce (e.g., inventory control systems), services sector (e.g., service data management systems, yield management systems), financial sector (e.g., systems for payment, retail, inventory, and risk management); public administration (e.g., e-government).

(f) e-Business and e-commerce systems, especially electronic marketplaces and auction systems, electronic stores, systems for catalog management, product configurations, order management, omnichannel commerce.

(g) Management information systems: analysis of information needs and products for management tasks, providing internal and external information, issue management and early warning systems, reporting systems, monitoring systems, planning systems. 
5.10 Knowledge Management and Collaborative Technologies

(a) Strategy and processes: knowledge management strategy; knowledge management success; knowledge management objectives; critical success factors; performance indicators; potential benefits; intellectual capital statements; knowledge management processes (localize and collect, exchange and distribute, benefit, (further) development); (business) process support through knowledge management; process-oriented knowledge management.

(b) Organization and culture: knowledge management organization; chief knowledge officer; knowledge workers; storytelling; knowledge bridge; knowledge management culture; incentive systems; motivation.

(c) Digital workgroups: communication; cooperation/collaboration; coordination; computerized working group (computer-supported cooperative work); media-choice theory; awareness management; unified communication.

(d) Digital communities: social media; enterprise social media; social media analytics (e.g., topic modeling, sentiment analysis, network analysis); social network sites; blogs; microblogging; wikis; forums; virtual worlds; online reviews.

(e) Management of digital content: content management systems; enterprise content management; content lifecycle; document management systems; metadata management; repository systems; user-generated content.

(f) Knowledge acquisition and knowledge sharing: skills management; skills lifecycle; individual and organizational learning; e-learning; learning-management systems; knowledge organization.

(g) Methods of knowledge management in weakly structured data stocks: knowledge modeling and visualization (e.g., ontologies, semantic web, topic maps, taxonomies); portals and search; text mining.

(h) Digital and collaborative innovation: open innovation/ideation; crowdsourcing; crowdtesting; crowdfunding.

(i) Integration with information systems within and external to companies: design and emergence of information systems; omnichannel management; shadow IT; (social) customer relationship management.

5.11 Model-Based Decision Support, Business Intelligence, and Analytics

(a) Types of decision problems, decision support systems. (b) Data preparation: visualization of input data, aggregation and disaggregation techniques, handling missing data.

(c) Mathematical-statistical models and methods of knowledge discovery in databases: e.g., forecasting, classification, clustering, regression, optimal experimental design, data mining, predictive modeling, text mining, opinion mining and sentiment analysis, process mining.

(d) Models and methods of operations research: optimization and simulation models from industry, commerce, and services sectors, solution methods from linear and mixed-integer optimization, sensitivity analysis, heuristics and metaheuristics and hybrid methods, discrete simulation, Monte Carlosimulation, simulation-based optimization.

(e) Models and methods of artificial intelligence and soft computing: e.g., software agents and multi-agent systems, evolutionary algorithms, machine learning methods such as artificial neural networks, fuzzy systems.

(f) Modeling and usage cycle: model selection, model creation, process selection, performance evaluation of decision models/algorithms, incorporating dynamics and stochastics into decision models (e.g., scenario management), parallelization algorithms.

(g) Using results: fully automated use vs. modification by human decision makers, dealing with dynamics and stochastics (e.g., rolling planning strategies, rescheduling).

(h) Cognitive science theories (e.g., cognitive-load theory, bounded-rationality theory, illusion-of-control theory), behavioral operations research, influence of emotions on decisions, human-centered management support, staff intelligence, game-based management support, collaborative business intelligence, selfservice business intelligence.

(i) Presentation of results: visual analytics, guidelines for the design of reports and business graphics, geographical analysis, dashboards.

(j) Technical perspective: decision architecture, e.g., entry-exit systems, method databases, integration of algorithmic kernels into existing application systems, parallelization strategies, distributed data analysis, mobile business intelligence, real-time business intelligence.

\subsection{Digital Transformation}

(a) Concept understanding, demarcation of information management, localization of phenomena and 
developments (sharing economy, crowdsourcing, newer forms of cooperation); relations to information economies: nature of information, information as a resource, economics of network effects, platforms, two-sided markets; access, control, and ownership; opening of resources; internal, external, shared resources; stages of the digital transformation, digitalization, and digital maturity of organizations.

(b) Value chain structures: value creation and value appropriation; IT-induced changes in the horizontal and vertical value-chain structure, e.g., newer forms of division of labor and knowledge transfer between stakeholders (companies, customers, etc.); interactive value: division of tasks, transaction costs, limits; hybrid coordination forms: virtual enterprise, supply chain/supply networks; business ecosystems.

(c) Business models: description approaches for business models; typical changes in the configuration of business models; incremental versus radical business model innovation; data-driven business models.

(d) Changes to primary activities: customer relationship management based on customer relationship management systems; recommendation systems and their impacts; search-engine marketing, individualization in production (mass customization); product-centric innovation approaches (e.g., smart objects).

(e) Changes to secondary activities: newer forms of recruitment; newer forms of product development (customer-centric), e.g., open innovation, commonsbased peer production, user innovation; individualization in communication and marketing.

(f) IT-induced changes in management, strategy, and the organization; capabilities for data collection and analysis and the implementation of data-based findings.

(g) Transformation management: digitization strategies and the demarcation of IT strategy; methods for promoting change (business patterns, business model innovation); newer role models (such as chief digital officer) and their cooperation with traditional IT roles; intrapreneurship and entrepreneurship, role of incubators, company builders etc.; business IT alignment: professional, social/organizational and cultural factors and hurdles in a digital transformation; role of IT environments, interaction with IT organizations, networking and their effects, e.g., the Internet of Things, cyber-physical systems.

(h) Effect of transformation on companies and industries: lifecycle model for business, specifics, and success factors for digital startups; specific developments in selected sectors (e.g., media and automotive). (i) Social implications of the digital transformation: protection of privacy, distribution and access to information, digital divide.

\section{Significant Training Content from Neighboring Disciplines}

To study BISE, knowledge of business administration and computer science is indispensable. These must be mandatory in every curriculum. It is assumed that one of these preconditions is met via the structure of the curriculum wherever BISE is a part of an economics or computer science degree.

\subsection{BISE for Non-economists}

If BISE is offered as part of or additionally to a non-economics degree (e.g., computer science, engineering), it is vital that the business administration components are firmly established in the curriculum. If these components are not covered outside of the subject of BISE per se, they must be taken up within the BISE part. This results in a higher amount of teaching hours for BISE. The business administration learning content cited in Sect. 5.2a and $\mathrm{b}$ are regarded as essential and indispensable.

\subsection{BISE for Non-computer Scientists}

If BISE is not offered as part of or additionally to a computer science degree, it is vital that the relevant computer science components are firmly established in the curriculum. If these components are not covered outside of the subject of BISE per se, they must be taken up within the BISE part. This results in a higher amount of teaching hours for BISE. The learning content cited in Sect. 5.3 is regarded as essential and indispensable, expanded upon with parts from Sect. 5.8 (such as software development and programming) that are usually taught within BISE modules.

\section{Curricula}

In this chapter, recommendations are given for the quantitative aspect of the curriculum. Given the diversity of variants of BISE education, this overview is limited to typical variations in the context of Bachelor's and Master's degrees in BISE, business administration, and computer science. In case of interdisciplinary degrees such as industrial engineering, the recommendations relating to the BISE and computer science proportions should be 
implemented analogously. Quantitative information (e.g., weighting, ECTS points) are to be understood as guidelines. Variations are possible in the specific curriculum design, depending on site-specific conditions.

\subsection{BISE Degrees}

For standalone programs leading to a degree in BISE, the basic concept remains that learning content from economics, computer science, and BISE per se should be represented in similar proportions, complemented by a fourth pillar of comparable size with foundations from mathematics, operations research, statistics, law, and behavioral sciences.

BISE per se is the terminology used to refer to learning content derived from the subject's position between its parent disciplines business administration and computer science (see Fig. 1). BISE per se includes the learning content shown in Sects. 5.1 and 5.5-5.12. Typical of this learning content is that it connects knowledge from business administration and computer science in a way not taught in the parent disciplines; or, it may be that they are taught, but not from the integrated perspective of BISE.

In addition to subject-specific skills, the study of BISE also seeks to teach social and personal skills to a sufficient extent. This can be achieved through appropriate teaching/ learning methods as part of academic courses or as part of dedicated courses. In the latter case, the required ECTS points must be reserved within the total quota.

\section{Bachelor's degree programs.}

A Bachelor's degree in BISE should cover all learning content presented in Chapter 5. According to the 4-pillar model - and after deduction of the work volume anticipated for the final thesis and internship - the subjects are to be designed according to the following proportions:

\begin{tabular}{lllll}
\hline & $\begin{array}{l}\text { Economics } \\
\text { fundamentals }\end{array}$ & $\begin{array}{l}\text { BISE } \\
\text { per se }\end{array}$ & $\begin{array}{l}\text { Foundations of } \\
\text { computer science }\end{array}$ & $\begin{array}{l}\text { Further } \\
\text { foundations }\end{array}$ \\
\hline Proportion & $25 \%$ & $25 \%$ & $25 \%$ & $25 \%$ \\
\hline
\end{tabular}

\section{Consecutive Master's degrees.}

A consecutive Master's degree in BISE expands on the content of previous undergraduate studies in BISE. Depending on the chosen duration of the Bachelor's degree, the duration of the Master's degree program is typically 3 or 4 semesters, and in some cases just 2 .

Because Bachelor's studies already lead to a degree which qualifies its holder for a professional occupation and which should, according to the recommendations above, cover all the learning content outlined in Chapter 5, a consecutive Master's degree must be based upon the same learning content at a more demanding, advanced level. Splitting the learning content into the Bachelor's degree and the Master's degree is not regarded as sensible, due to the requirements of a Bachelor's degree to qualify its holder for a professional occupation.

In a Master's degree program, it is recommended to shift the even distribution of the courses from a model which supports the four pillars towards one which focuses on BISE per se. Furthermore, in specific cases specializations in subdomains of BISE are possible.

The subject area proportions in a consecutive Master's degree should be set approximately as follows:

\begin{tabular}{lllll}
\hline & $\begin{array}{l}\text { Economics } \\
\text { foundations }\end{array}$ & $\begin{array}{l}\text { BISE } \\
\text { per se }\end{array}$ & $\begin{array}{l}\text { Foundations of } \\
\text { computer science }\end{array}$ & $\begin{array}{l}\text { Further } \\
\text { foundations }\end{array}$ \\
\hline Proportion & $20 \%$ & $50 \%$ & $20 \%$ & $10 \%$ \\
\hline
\end{tabular}

The learning content in each pillar should, as mentioned above, demonstrate a more advanced level of aspiration. The word foundations has been retained in the pillar names to ensure consistency with the main educational areas mentioned in Chapter 5.

3. Non-consecutive Master's degrees.

A non-consecutive Master's degree in BISE is a standalone degree program in which previous undergraduate studies do not need to have been in the same subject. Because it is in principle open to graduates of any subject, especially non-economists and non-computer scientists, the 4-pillar model mentioned at the outset is to be used.

As a rule, Master's degrees last 2, 3, or 4 semesters. However, since all the essential learning content of BISE must be taught, a regular arrangement in four semesters is recommended. Shorter periods are only considered if the degree is designed for a target group that already brings with it knowledge of a part of the learning content, e.g., a non-consecutive BISE Master's degree program for students with a Bachelor's degree in business administration or computer science. 
For a standalone Master's degree program with 4 semesters, the topic distribution should be set approximately as follows:

\begin{tabular}{lllll}
\hline & $\begin{array}{l}\text { Economics } \\
\text { fundamentals }\end{array}$ & $\begin{array}{l}\text { BISE } \\
\text { per se }\end{array}$ & $\begin{array}{l}\text { Foundations of } \\
\text { computer science }\end{array}$ & $\begin{array}{l}\text { Further } \\
\text { foundations }\end{array}$ \\
\hline Proportion & $25 \%$ & $25 \%$ & $25 \%$ & $25 \%$ \\
\hline
\end{tabular}

\subsection{BISE in Business Degree Programs}

As part of business degree programs, BISE components can be taught in foundational, core, in-depth and specialization studies and stipulations regarding study hours can be made in the form of ECTS points.

- Foundational studies include the broad training that all business students should be exposed to.

- Core studies include the core content that students focusing BISE should master.

- Advanced and specialization studies contain topics that expand upon, selectively add to, or partially replace core studies.

1. BISE in Business Administration Bachelor's Degree Programs.

Applying the principles of division into foundational, core, and advanced/specialization studies to a Bachelor's degree in business administrations, the proportions should - depending on scope (length of the Bachelor's degree) be set approximately as follows:

\begin{tabular}{llll}
\hline Duration & $\begin{array}{l}\text { Foundational } \\
\text { studies } \\
\text { (ECTS) }\end{array}$ & $\begin{array}{l}\text { Core } \\
\text { studies } \\
\text { (ECTS) }\end{array}$ & $\begin{array}{l}\text { Advanced and } \\
\text { specialization studies } \\
\text { (ECTS) }\end{array}$ \\
\hline 6 & $6-12$ & $18-24$ & $8-12$ \\
7 & $9-15$ & $21-27$ & $10-15$ \\
8 & $12-18$ & $24-30$ & $10-15$ \\
\hline
\end{tabular}

Foundational studies cover selected learning content from the following main educational areas:

- Subject and context (Sect. 5.1).

- Foundations of computer science (Sect. 5.3) including learning a programming language (optional during foundational studies).

- Data models and database systems (Sect. 5.5a).

- Modeling and investigating processes (Sect. 5.6c).

- Corporate core systems (Overview/selection) (Sect. 5.9).

- Digital transformation (Overview/selection) (Sect. 5.12).
Core studies should, within the limits of available ECTS points, deal with an overview of the main learning content in the following main educational areas, to the extent that these are not already the subject of the foundational studies:

- Data management (Sect. 5.5).

- Process management (Sect. 5.6).

- Information management (Sect. 5.7).

- Development and operation of information systems (Sect. 5.8).

- Digital transformation (Sect. 5.12).

If the available ECTS quota enforces core priorities, then these should be on the following main educational areas:

- Data management (Sect. 5.5).

- Process management (Sect. 5.6).

- Information management (Sect. 5.7).

Learning and using a programming language is to be made mandatory, if this is not something which is already part of the foundational studies.

Advanced and specialization studies can, depending on the options and preferences of teaching staff and students, set further core themes or adopt learning content which, due to the reduced quota, is no longer part of core studies. Additionally, the learning content of the following main educational areas present themselves as options for advanced and specialization studies:

- Knowledge management and collaborative technologies (Sect. 5.10).

- Model-based decision support, business intelligence, and analytics (Sect. 5.11).

2. BISE in Business Administration Master's Degree Programs.

The shape of BISE education within a business administration Master's degree program depends, among other things, on whether this is consecutive or standalone and on the period over which it is structured.

In a consecutive Master's degree program, it is assumed that the foundational studies described under point 1 . have been completed.

The curriculum in BISE must be configured from the learning content in the main educational areas according to Sects. 5.1 to 5.12, depending on whether students had studied the core studies and, where relevant, the advanced and specialization studies.

In a standalone Master's degree program, the content of foundational studies in BISE should be a precondition. If students do not meet this requirement, the essential learning content of the foundational studies can be taught as a preparatory introduction. 
If the consecutive or standalone Master's degree program sets priorities, the proportions should be approximately set as follows:

\begin{tabular}{lll}
\hline $\begin{array}{l}\text { Duration } \\
\text { (Semester) }\end{array}$ & $\begin{array}{l}\text { Compulsory BISE courses } \\
\text { (ECTS) }\end{array}$ & $\begin{array}{l}\text { Advanced BISE courses } \\
\text { (ECTS) }\end{array}$ \\
\hline 4 & 18 & 24 \\
3 & 15 & 18 \\
2 & 12 & 12 \\
\hline
\end{tabular}

\subsection{BISE in Computer Science Degree Programs}

Within computer science degrees, BISE is usually found in the form of an elective or secondary subject. As indicated in Sect. 6.1, attention must be paid to non-economics courses to sufficiently embed business administration learning content. As it is further assumed that the computer science learning content is already covered by the structure of the program, attention must also be paid to learning content from BISE per se.

\section{BISE in Computer Science Bachelor's Degree Programs.}

The business administration foundations named in Sect. 5.2a) must be included as the business administration learning content of a computer science degree program.

For the subject of BISE per se, learning content from the following main education areas is to be provided:

- Subject and context (Sect. 5.1).

- Information management (Sect. 5.7).

- Corporate core systems (Sect. 5.9).

- Model-based decision support, business intelligence, and analytics (Sect. 5.11).

It is assumed that the learning content of the main educational areas is sufficiently covered in the computer science part of the degree, as per Sects. 5.3, 5.5, and 5.8. Otherwise, these must be taught within the framework of BISE per se.

For BISE as an elective or secondary subject within a computer science Bachelor's degree program, the distribution of subjects is to be - depending on the selected duration - set approximately according to the following proportions:

\begin{tabular}{lll}
\hline $\begin{array}{l}\text { Duration } \\
\text { (Semester) }\end{array}$ & $\begin{array}{l}\text { Compulsory BISE courses } \\
\text { (ECTS) }\end{array}$ & $\begin{array}{l}\text { Advanced BISE courses } \\
\text { (ECTS) }\end{array}$ \\
\hline 6 & 24 & 24 \\
7 & 27 & 27 \\
8 & 30 & 30 \\
\hline
\end{tabular}

2. BISE in Computer Science Master's Degree Programs

If BISE is designed as a core element or elective in a Master's degree program in computer science, then the BISE aspects are to be structured in accordance with the assumptions from Sect. 6.1.

If students do not have sufficient knowledge of business administration and BISE from their previous studies or relevant professional activities, the proportions of each of these subjects should not fall below a value of 18 ECTS.

\section{Organizational Forms of the Educational Program}

\subsection{Universities}

Alongside lectures, BISE education must involve many exercises both within and outside the university.

Modules with computer use such as software internships, project seminars, workshops, programming courses, exercises in computer labs, etc. are typical. These modules - for which a proportion of at least $40 \%$ is to be targeted require a high degree of supervision. To ensure this, they should be held in groups of no more than 20 students. Internet-based forms of education (e-learning, virtual classes) can be usefully applied, as BISE students generally have a high affinity for technology.

In a Bachelor's or Master's degree program in BISE, at least one of the modules must be a project seminar totaling approximately 12 ECTS points and within which an integration of the learning content takes place. If BISE is part of another degree program, a project seminar should be provided in accordance with the available ECTS quota. Furthermore, it is considered worthwhile to embed as mandatory at least one seminar into the curriculum with written work, a presentation, and discussion. This helps to strengthen the skills regarding presentation and written expression.

With regard to a future career, it is recommended that both the Bachelor's and Master's degree programs include an internship of at least 12 weeks. In a Master's degree program, this may be omitted if the student, after completing Bachelor's studies, already acquired relevant professional experience of at least the same duration.

If conditions permit, the length of time for which students work on their final (Bachelor's or Master's) theses should, in practice, be at least six months.

\subsection{Universities of Applied Sciences}

BISE education at universities of applied sciences is characterized by a more practical focus. Accordingly, for a 
substantial amount of the modules in a BISE curriculum, lectures should be supplemented with exercises or internships. These should have in total roughly the same volume as the lectures themselves. Each Bachelor's and Master's degree program should include projects that, where possible, are carried out in cooperation with companies. Projects in a research setting are also possible, in particular for Master's degrees. Theses should be preferably conducted with a strong practical focus and carried out whenever possible in cooperation with companies.

Open Access This article is distributed under the terms of the Creative Commons Attribution 4.0 International License (http://crea tivecommons.org/licenses/by/4.0/), which permits unrestricted use, distribution, and reproduction in any medium, provided you give appropriate credit to the original author(s) and the source, provide a link to the Creative Commons license, and indicate if changes were made.

\section{References}

1. IS (2010) Curriculum guidelines for undergraduate degree programs in information systems (2010). http://www.acm.org/educa tion/curricula/IS\%202010\%20ACM\%20final.pdf Accessed 16 Nov 2016

2. MSIS (2016) Global competency model for graduate degree programs in information systems (2016). https://msis2016review. wordpress.com Accessed 16 Nov 2016

3. Rahmenempfehlung für die Ausbildung in Wirtschaftsinformatik an Hochschulen (2017). https://www.gi.de/fileadmin/redaktion/ empfehlungen/Empfehlung-Wirtschaftsinformatik2017.pdf Accessed 16 Mar 2017

4. Profil der Wirtschaftsinformatik (2011). http://wi.vhbonline.org/ fileadmin/Kommissionen/WK_WI/Profil_WI/Profil_WI_final_ds26. pdf Accessed 19 Sept 2016 